BNL-114721-2017-JA

File \# 95729

\title{
In situ examination of osteoblast biomineralization on SPS-modified substrates using Fourier transform infrared microspectroscopy
}

\author{
Y. Meng, L. M. Miller
}

Submitted to: Biointerphases

July 1, 2017

Photon Sciences Department

Brookhaven National Laboratory

\section{U.S. Department of Energy \\ USDOE Office of Science (SC), Basic Energy Sciences (BES) (SC-22)}

Notice: This manuscript has been authored by employees of Brookhaven Science Associates, LLC under Contract No. DE- SC0012704 with the U.S. Department of Energy. The publisher by accepting the manuscript for publication acknowledges that the United States Government retains a non-exclusive, paid-up, irrevocable, world-wide license to publish or reproduce the published form of this manuscript, or allow others to do so, for United States Government purposes. 


\section{DISCLAIMER}

This report was prepared as an account of work sponsored by an agency of the United States Government. Neither the United States Government nor any agency thereof, nor any of their employees, nor any of their contractors, subcontractors, or their employees, makes any warranty, express or implied, or assumes any legal liability or responsibility for the accuracy, completeness, or any third party's use or the results of such use of any information, apparatus, product, or process disclosed, or represents that its use would not infringe privately owned rights. Reference herein to any specific commercial product, process, or service by trade name, trademark, manufacturer, or otherwise, does not necessarily constitute or imply its endorsement, recommendation, or favoring by the United States Government or any agency thereof or its contractors or subcontractors. The views and opinions of authors expressed herein do not necessarily state or reflect those of the United States Government or any agency thereof. 


\section{In situ examination of osteoblast biomineralization on SPS-modified substrates using Fourier transform infrared microspectroscopy}

Running title: In situ examination of osteoblast biomineralization using FTIR

Running Authors: Meng et al.

Yizhi Meng $^{\text {a) }}$

Department of Materials Science and Chemical Engineering, Stony Brook University, 314 Old Engineering, Stony Brook, New York 11794-2275, USA

\section{Meghan E. Faillace}

Department of Biomedical Engineering, Stony Brook University, Stony Brook, New York 117945281, USA

\section{Kathryn Dorst}

Department of Materials Science and Chemical Engineering, Stony Brook University, Stony Brook, New York 11794-2275, USA

\section{Samantha J. Palmaccio}

Department of Materials Science and Chemical Engineering, Stony Brook University, Stony Brook, New York 11794-2275, USA

Lisa M. Miller

Photon Sciences, Brookhaven National Laboratory, Upton, New York 11973, USA

$$
\text { Yi-Xian Qin }
$$

Department of Biomedical Engineering, Stony Brook University, Stony Brook, New York 117945281, USA

\footnotetext{
a)Electronic mail: yizhi.meng@stonybrook.edu
} 
Osteoporosis is a skeletal disorder that is characterized by the loss of bone mineral density (BMD) resulting in increased risk of fracture. However, it has been shown that BMD is not the only indicator of fracture risk, as the strength of bone depends on a number of factors, including bone mass, architecture and material properties. Physiological mineral deposition requires the formation of a properly developed extracellular matrix (ECM), which recruits calcium and phosphate ions into the synthesis of apatite crystals. Temporal and spatial compositional and structural changes of biological apatite greatly depend on the properties of the crystals initially formed. As such, Fourier-transform infrared microspectroscopy (FTIRM) is capable of examining adaptive remodeling by providing compositional information such as the level of mineralization and carbonate substitution, as well as quality and perfection of the mineral phase. The objective of this study was to evaluate the in vitro mineralization development of MC3T3-E1 murine calvarial pre-osteoblasts cultured on different substrata by comparing FTIRM measurements from two subclones (mineralizing subclone 4 and nonmineralizing subclone 24) maintained in culture for up to 21 days. The results showed that modulation of the substrate surface using a thin coating of sulfonated polystyrene (SPS) provided favorable conditions for the development of a mineralizable ECM and that the mineral formed by the osteoblasts was similar to that of fully mineralized bone tissue. Specifically, the mineralizing subclone produced significantly more mineral phosphate when cultured on SPS-coated substrates for 21 days, compared to the same culture on bare substrates. In contrast, the level of mineralization in nonmineralizing subclone was low on both SPS-coated and uncoated substrates. The mineralizing subclone also produced comparable amounts of collagen on both substrates, however 
mineralization was significantly higher in the SPS culture. The nonmineralizing subclone produced comparable amounts of collagen on day 1 but much less on day 21. Collagen maturity ratio increased in the mineralizing subclone from day 1 to day 21 , but remained unchanged in the nonmineralizing subclone. These results suggest that SPS-treatment of the substrate surface may alter collagen remodeling, however other factors may also influence osteoblast mineralization in the long term.

Keywords: osteoblasts, mineralization, Fourier transform infrared imaging, sulfonated polystyrene

\section{INTRODUCTION}

Osteoporosis is a skeletal disorder that is characterized by low bone mass and enhanced bone fragility resulting in increased risk of fracture during daily activity. It is particularly prominent in postmenopausal women and the elderly ("primary" osteoporosis), but is also seen in patients of clinical disorders such as thyrotoxicosis ("secondary" osteoporosis) ${ }^{1}$. More important than the loss of bone mass is the decrease of mineral in bone tissue, and much effort has been directed toward the mapping of the mineralization in bone in the last few decades. Clinical diagnostic tools for the loss of bone mass such as dual energy X-ray absorptiometry provide a reliable assessment of bone mineral density (BMD). However, it has been shown that BMD is not the only indicator of fracture risk, as the strength of bone depends on a number of factors, including bone mass, architecture and material properties ${ }^{2}$. 
The process of physiological mineral deposition requires many cellular and extracellular factors ${ }^{3}$. An initial network of collagen in the extracellular matrix (ECM) is essential for the deposition of physiological, rather than dystrophic, mineral ${ }^{3,4}$. The ECM also requires a properly developed fibrillar network for mineralization to occur correctly ${ }^{5}$. Subsequently, calcium and phosphate ions circulating in the intracellular space and/or extracellular fluid are recruited into the synthesis of apatite crystals. These crystals are highly amorphous and typically orient themselves within the collagenous matrix ${ }^{6}$. Compositional and structural changes of biological apatite greatly depend on the properties of the crystals initially formed, which are influenced by the surrounding fluid 7. The murine calvarial MC3T3-E1 cell line forms a bone-like mineralized ECM and is a widely accepted model system for studying osteogenic development ${ }^{8}$.

Fourier-transform infrared microspectroscopy (FTIRM) can assist in the examination of bone remodeling by providing spatially-resolved information on the level of mineralization, carbonate substitution, mineral crystallinity, and collagen structure with minimal disturbance to the cell culture ${ }^{9,10}$. Moreover, use of a synchrotron IR source can improve both the spatial resolution and spectral range of the technique, allowing for the use of a smaller sample size and higher detection sensitivity than conventional laboratory FTIRM. Numerous synchrotron FTIRM studies have reported the mineral quality of bone, cartilage, and dental enamel ${ }^{7,11-14}$, and the mineral phase in calcified tissues has thus far been shown to be a poorly crystalline, carbonate-containing analog of naturally occurring hydroxyapatite ${ }^{15}$. More knowledge regarding the in-situ spatial and temporal distribution of biological apatite in mineralizing osteoblasts would facilitate a better 
understanding of the protein-mineral interrelationships of bone as well as its early-stage mineralization mechanisms.

Our group previously showed that when cultured on synthetic substrates such as silicon, mineralization of osteoblasts can be impaired unless the surface is functionalized with a thin film of sulfonated polystyrene (SPS) ${ }^{5}$. Without the SPS coating, preosteoblasts did not produce a fibrillar ECM network in silico and failed to deposit apatitic mineral. We hypothesized that SPS would also enhance the biomineralization of osteoblasts on IR-reflective substrates. The purpose of this work was therefore to evaluate the spatial and temporal development of cultured osteoblasts on infrared reflective "MirrIR" microscope slides. To this end, we compared FTIRM measurements from two subclones of MC3T3-E1 murine calvarial osteoblasts (mineralizing subclone 4 and non-mineralizing subclone 24) that were directly cultured on either native or SPScoated indium tin-oxide (ITO) MirrIR slides for up to 21 days.

\section{EXPERIMENTAL}

\section{A. Cell culture}

Two subclones of MC3T3-E1 cells (mineralizing and non-mineralizing) were maintained at $37^{\circ} \mathrm{C}\left(5 \% \mathrm{CO}_{2}\right.$, humidified $)$ in $\alpha$-MEM culture medium supplemented with 10\% fetal bovine serum (FBS) (Hyclone, Logan, UT), 100 units/mL penicillin and 100

$\mu \mathrm{g} / \mathrm{mL}$ streptomycin (Invitrogen), $50 \mu \mathrm{g} / \mathrm{mL}$ L-ascorbic acid (Sigma, St. Louis, MO) and 4 mM $\beta$-glycerophosphate (Sigma). Fresh medium was given every 2 or 3 days. Cells 
were seeded at an initial density of 50,000 cells per $\mathrm{cm}^{2}$ in 6 -well tissue culture plates (BD Biosciences, Franklin Lakes, NJ).

\section{B. Substrate preparation}

Infrared reflective "MirrIR" microscope slides (Kevley Technologies, Chesterland, $\mathrm{OH})$ were partitioned into $20 \mathrm{~mm}$ x $20 \mathrm{~mm}$ pieces, cleaned with $100 \%$ ethyl alcohol, and spincoated with sulfonated polystyrene (SPS) for 30 seconds at $1000 \mathrm{rpm}$. SPS has been shown to be a critical surface for inducing a fibrillar network of osteoblast extracellular matrix proteins. This ECM network is needed for subsequent calcification of the

mineralization stage ${ }^{5}$. A separate batch of uncoated MirrIR slides was autoclaved prior to cell culture.

\section{Water contact angle (WCA)}

Wettability is a useful metric of materials properties and can be used to measure the intrinsic hydrophilicity (contact angles less than $90^{\circ}$ ) or hydrophobicity (contact angles greater than $90^{\circ}$ ) of a surface ${ }^{16}$. In our study, the static contact angles of sessile drops of deionized (DI) water on uncoated and SPS-coated MirrIR glass slides were measured using CAM 200 Optical Angle Meter (KSV Instruments Ltd.) in air at room temperature. A drop of $10 \mu \mathrm{L}$ DI water was added vertically onto the dry surface, and contact angles were measured immediately. Five drops were averaged as the final contact angle for each substrate.

\section{FTIR characterization of osteogenic differentiation} Synchrotron Fourier-transform Infrared Microspectroscopy (FTIRM) experiments were carried out using a Thermo Nicolet Continu $\mu \mathrm{m}$ infrared microscope coupled to a Nicolet Magna 860 FTIR (Thermo Nicolet Instruments, Madison, WI, USA) at beamline 
U10B located at the National Synchrotron Light Source (NSLS) at Brookhaven National Laboratory (BNL, Upton, NY). Measurements were performed in transflectance mode with an aperture of $15 \times 15 \mu \mathrm{m}$ where the background was collected from a clean MirrIR slide. MC3T3-E1 cells cultured for up to 21 days on either SPS-coated or uncoated MirrIR substrates and were rinsed with DI water, fixed with 100\% ethyl alcohol and airdried. Point spectra were collected with a square aperture of $15 \mu \mathrm{m}$ so that the aperture enclosed the area taken up by an individual cell, at $8 \mathrm{~cm}^{-1}$ resolution, totaling 128 scans per pixel. These data were used for evaluating collagen maturity.

IR image maps were also collected at beamline U2B using a conventional globar source in a Spectrum Spotlight infrared microscope (Perkin Elmer, Wellesley, MA) in transflectance mode with a pixel size of $6.25 \times 6.25 \mu \mathrm{m}$, in a $200 \mu \mathrm{m}$ x $200 \mu \mathrm{m}$ region of the sample (to encompass a larger field of view) at $8 \mathrm{~cm}^{-1}$ resolution, accumulating 16 scans per pixel. These data were used for calculate mineral-to-matrix ratio and collagento-protein ratio.

Peak areas and heights of interest from the globar FTIRM spectra were integrated using the OMNIC Macros\Basic software (Thermo Electron Corp., Waltham, MA). Data were averaged in Excel (Microsoft, Seattle, WA). The level of mineralization was determined by calculating the peak area under the $v_{1,} v_{3}$ phosphate region $\left(1060-990 \mathrm{~cm}^{-1}\right.$; linear baseline: $1060-990 \mathrm{~cm}^{-1}$ ) and normalizing to the peak area under the amide I region (1700-1600 $\mathrm{cm}^{-1}$; linear baseline: $1800 \mathrm{~cm}^{-1}$ ) (Fig. 1). Collagen accumulation was determined based on the C-H wagging/deformation peak $\left(1350-1325 \mathrm{~cm}^{-1}\right.$; baseline $1360-1325 \mathrm{~cm}^{-1}$ ) that is unique to collagen ${ }^{10,17}$. Peak-fitting based on second derivative spectrum was used to evaluate collagen maturity. Specifically, the ratio of the areas 
underlying the peaks associated with mature $\left(\sim 1660 \mathrm{~cm}^{-1}\right)$ and immature $\left(\sim 1690 \mathrm{~cm}^{-1}\right)$ crosslinks was calculated (Fig. 2). 

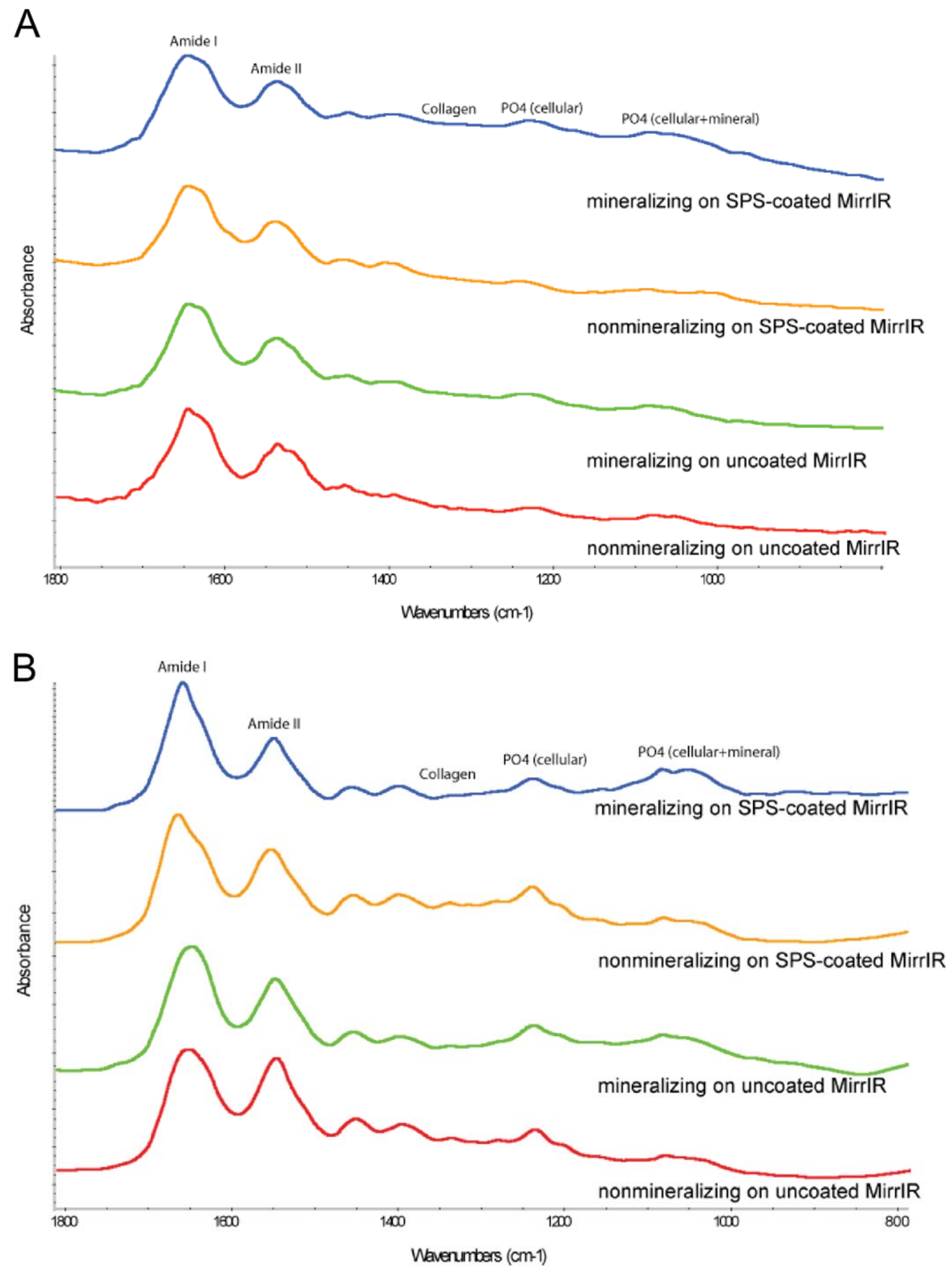

Figure 1. Globar Fourier-transform infrared microspectroscopy spectra of MC3T3-E1 cells cultured on uncoated and SPS-coated MirrIR slides at (A) day 1 and (B) day 21. 


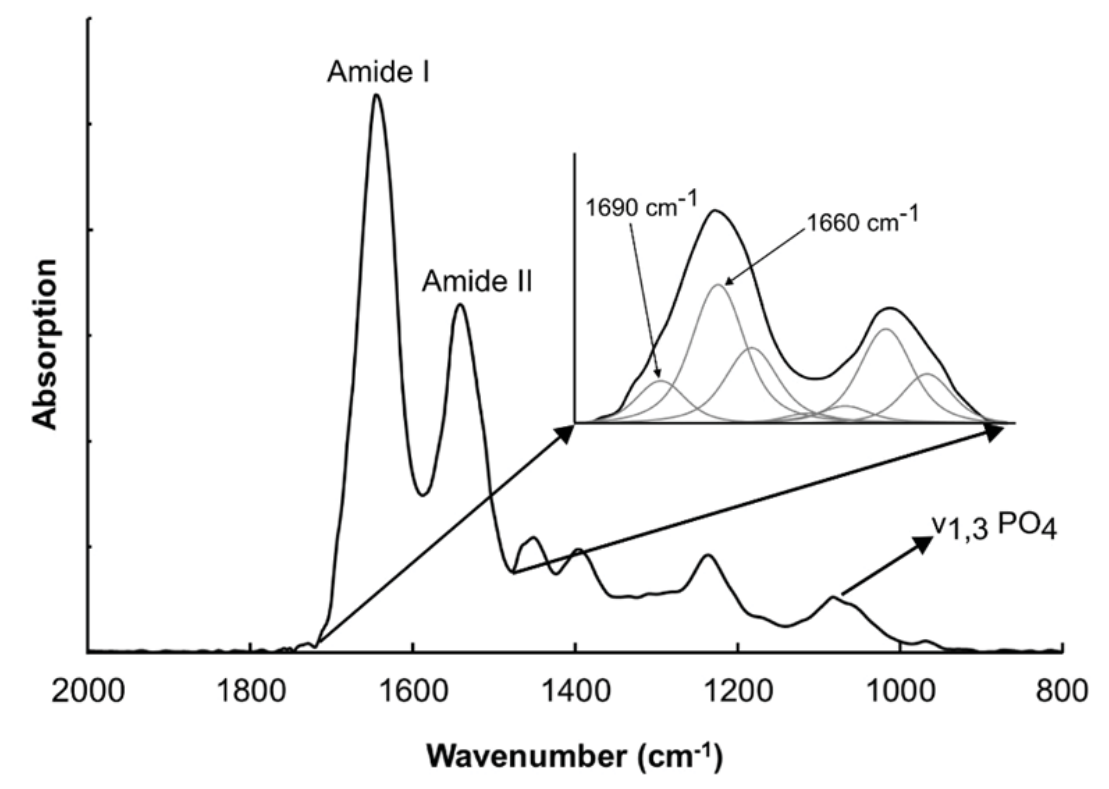

Figure 2. Representative IR spectrum of mineralized MC3T3-E1 cell culture. The peakfitting for determination of collagen cross-linking is done for area of $1750-1480 \mathrm{~cm}^{-1}$. The inset shows a typical fit to this area. The peaks representing mature $\left(\sim 1660 \mathrm{~cm}^{-1}\right)$ and immature $\left(\sim 1690 \mathrm{~cm}^{-1}\right)$ cross-links are indicated.

\section{E. Statistics}

All data were analyzed by analysis of variance (ANOVA) using Microsoft Excel.

\section{RESULTS}

\section{A. Substrate wettability}

Uncoated MirrIR slides were found to have a relatively lower water contact angle (WCA), around $42^{\circ}$ (Table 1). SPS-coated MirrIR slides had a higher WCA, of about $64^{\circ}$. 
Table 1. Water contact angles of untreated MirrIR glass slides and MirrIR slides coated with sulfonated polystyrene (SPS).

\begin{tabular}{|l|l|}
\hline Surface & WCA $\left(^{\circ}\right)$ \\
\hline Uncoated MirrIR & $41.7 \pm 0.4$ \\
\hline SPS-coated MirrIR & $64.1 \pm 0.4$ \\
\hline
\end{tabular}

\section{B. Mineral accumulation in osteoblast culture}

The raw globar FTIRM spectra obtained from mineralizing and nonmineralizing osteoblast cultures on both SPS-coated and uncoated MirrIR slides exhibited typical peaks for collagen (i.e., amide I and amide II protein bands) and cellular phosphate (Fig. 1). No prominent $v_{1}, v_{3}$ mineral phosphate peaks were visible in any of the day 1 cultures (Fig. 1a), while a moderate mineral phosphate peak was visible in the day 21 mineralizing cells on SPS, particularly in the mineralizing cells on SPS-coated MirrIR (Fig. 1b). As a positive control, a synchrotron FTIRM spectrum was also collected from a 28-day sample of the mineralizing MC3T3-E1 cells, which shows prominent mineral phosphate peaks in the $1060-990 \mathrm{~cm}^{-1}$ region (Fig. 3). The $v_{1}, v_{3}$ phosphate band seen in the 28-day mineralizing cells has the same shape as the $v_{1}, v_{3}$ phosphate peak seen in fully mineralized bone (Fig. 3). Additionally, when compared to crystalline hydroxyapatite, octacalcium phosphate, and amorphous calcium phosphate, the mineral formed by the 28day cell culture appears most like crystalline hydroxyapatite (Fig. 3). 


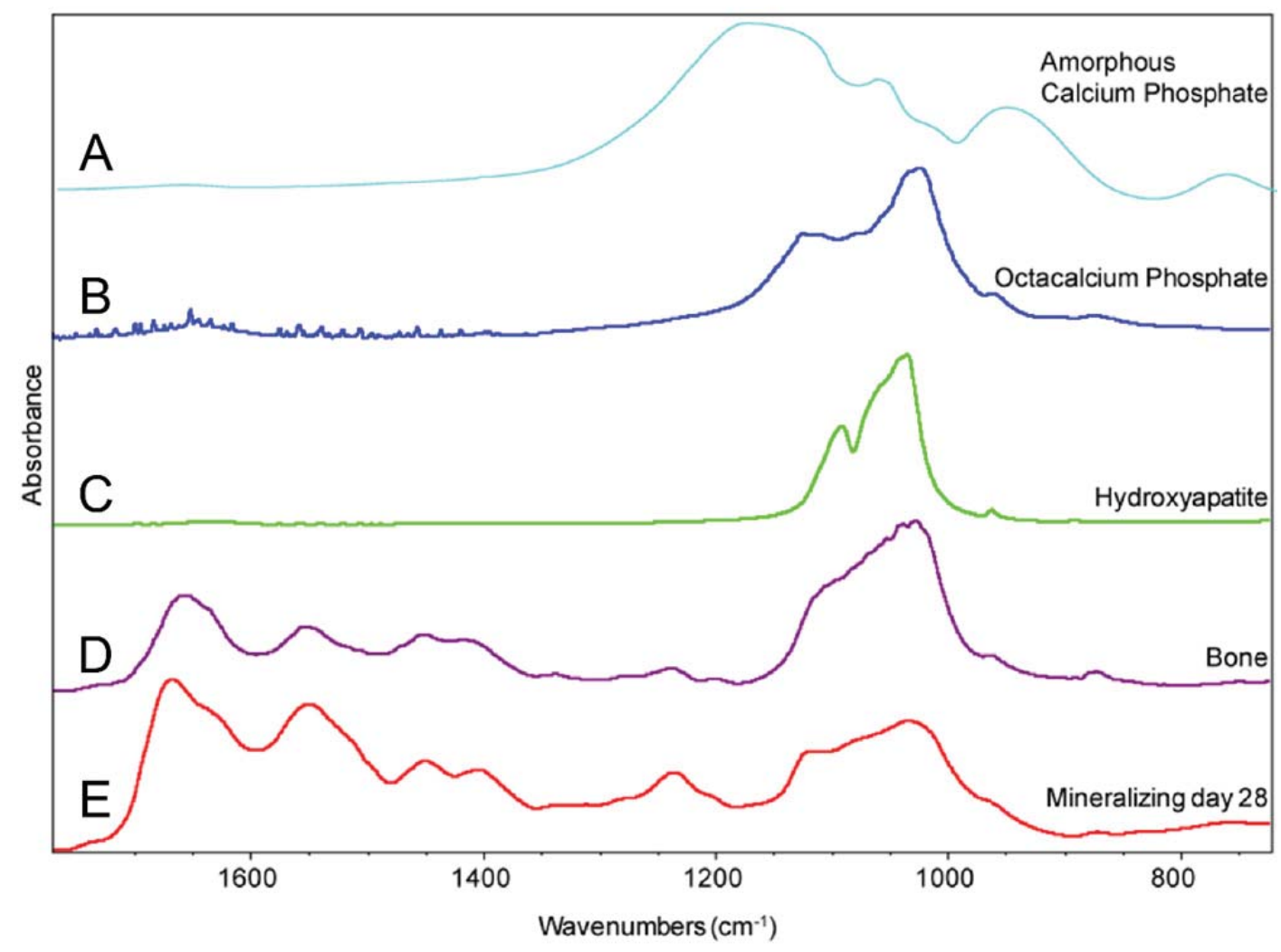

Figure 3. (A) Synchrotron Fourier-transform infrared (FTIR) spectrum of amorphous calcium phosphate. (B) FTIR spectrum of commercial octacalcium phosphate. (C) FTIR spectrum of commercial crystalline hydroxyapatite. (D) FTIR spectrum of bone from the right iliac crest of a mature beagle. (E) FTIR spectrum of mineralizing MC3T3-E1 cells after 28 days of culture.

The amount of mineral accumulated in the extracellular matrix was computed by normalizing the area under the phosphate peak $\left(1060-990 \mathrm{~cm}^{-1}\right)$ to total protein (amide I, 1700-1600 $\mathrm{cm}^{-1}$ ) (Fig. 4). Negligible amounts of mineral phosphate were found in both osteoblast subclones on either substrate on day 1 (Fig. 4). It also appears that the phosphate:protein ratio of the mineralizing subclone of MC3T3-E1 cells cultured on SPScoated MirrIR was significantly less than the other groups $(\mathrm{p}<0.001)$, possibly due to the relative abundance of ECM proteins produced at this early stage. On day 21, substantial amounts of mineral phosphate were found in the mineralizing cultures, particularly on the 
SPS-coated substrate (Fig. 4). Specifically, mineralizing MC3T3-E1 cultured on SPScoated MirrIR slides produced 26\% more mineral phosphate $(\mathrm{p}<0.001)$

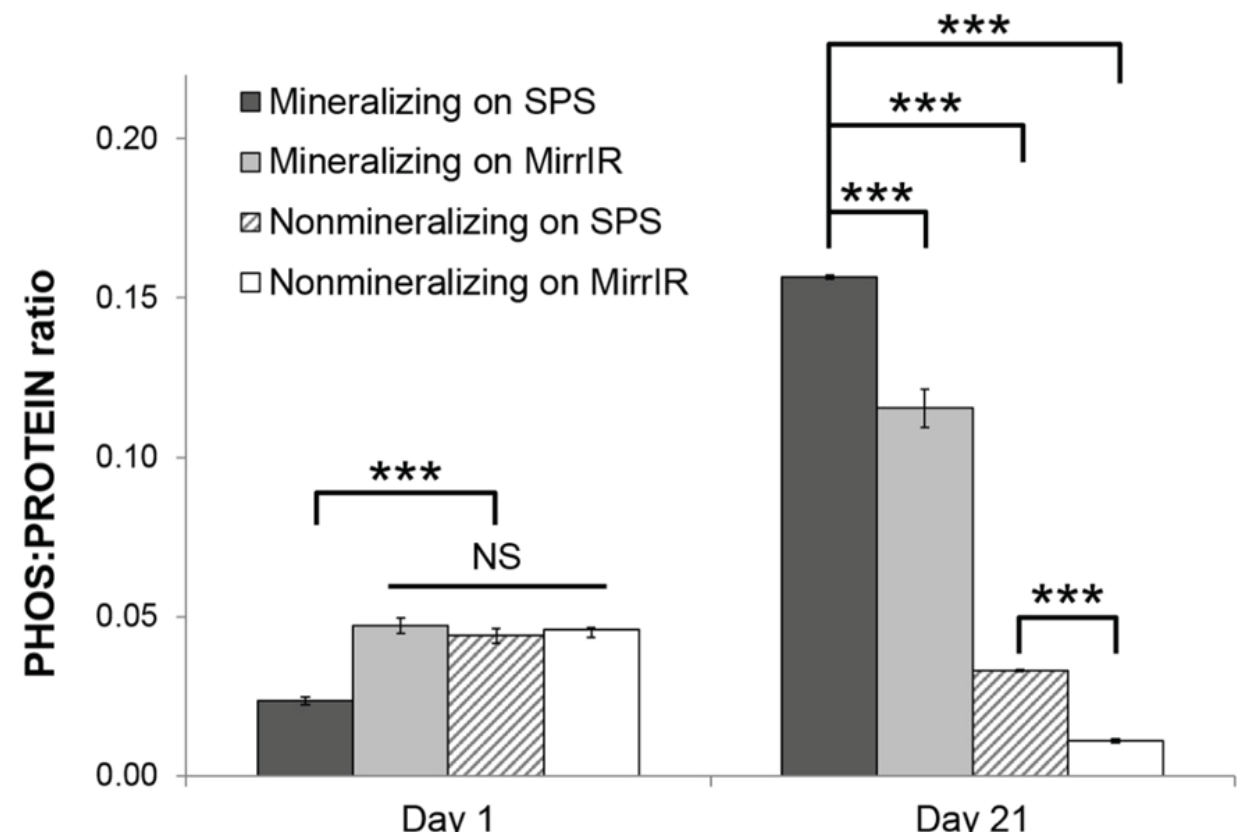

Figure 4. Level of mineralization (mean $\pm \mathrm{SE}$ ) calculated from phosphate $\left(1060-990 \mathrm{~cm}^{-}\right.$ $\left.{ }^{1}\right)$ to protein $\left(1700-1600 \mathrm{~cm}^{-1}\right)$ ratios in mineralizing and nonmineralizing MC3T3-E1 cells on (A) SPS-coated and (B) uncoated MirrIR slides. Data were collected at beamline U2B at the NSLS. Levels of statistical significance are indicated by single $\left({ }^{*}, \mathrm{p}<0.05\right)$, double $(* *, \mathrm{p}<0.01)$, or triple $(* * *, \mathrm{p}<0.001)$ asterisks.

compared to the same cell lines cultured on uncoated MirrIR slides (Fig. 4). Collectively, the mineralizing subclone produced $70-90 \%$ more mineral phosphate compared to the non-mineralizing subclone after 3 weeks of culture (Fig. 4). The amount of phosphate produced by the nonmineralizing subclone is considerably lower, which was expected ${ }^{4}$.

\section{Spatial and temporal development of mineral phosphate}


From the phosphate:protein spatial maps it can be seen that there were negligible amounts of mineral phosphate on day 1 in the extracellular matrix (ECM) of the mineralizing subclone cultured on SPS (Fig. 5a-h). On day 21, however, there was an

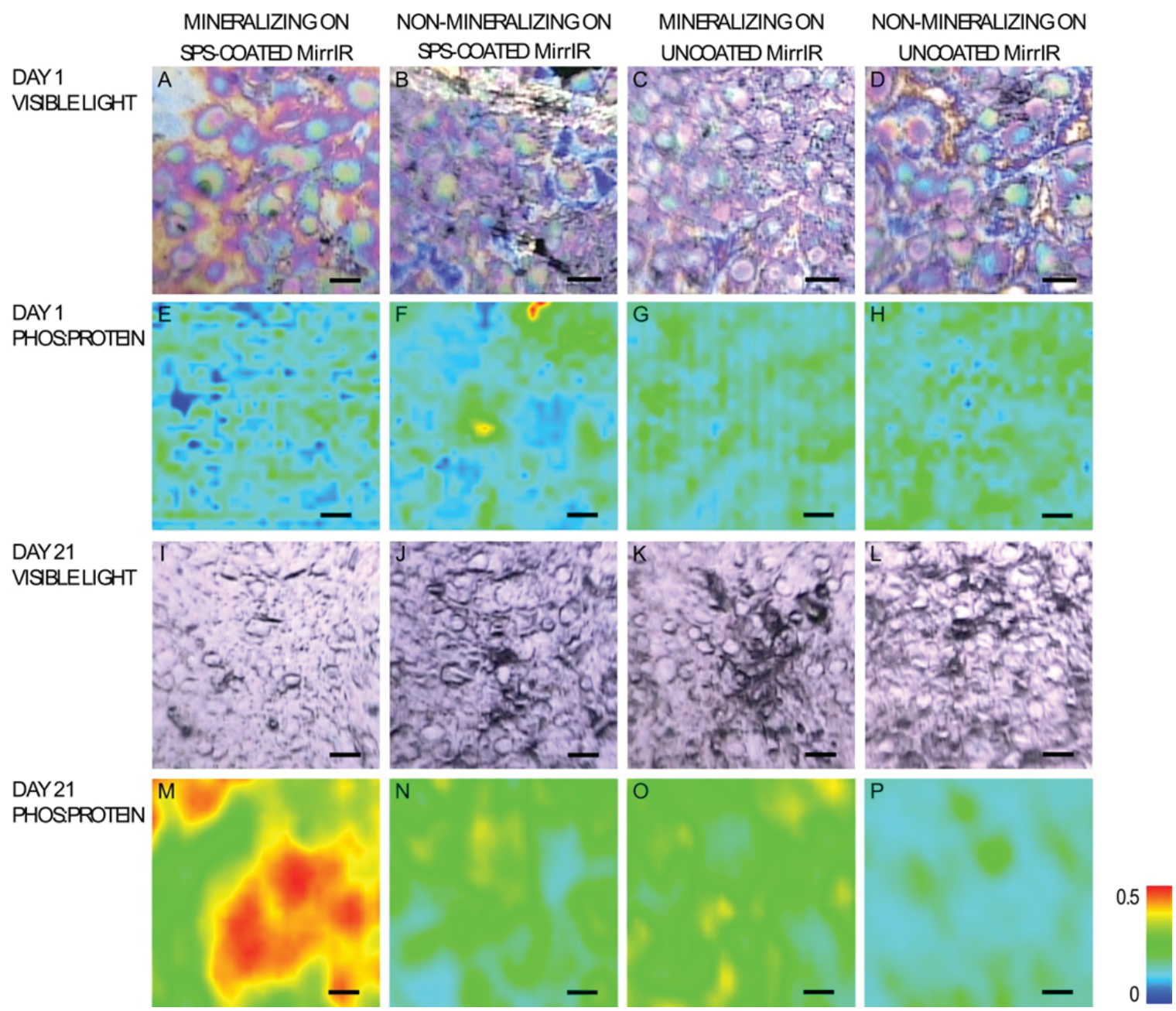

Figure 5. Light micrographs (A-D, I-L) and FTIRM maps (E-H, M-P) showing cell morphology and phosphate:protein ratio of 1- and 21-day mineralizing and nonmineralizing osteoblasts cultured on SPS-coated and uncoated MirrIR slides. Color scale is in arbitrary units (a.u.). Baseline was provided by a spectrum collected in air only (no cells). Bars, $25 \mu \mathrm{m}$.

appreciable amount of mineral phosphate in the mineralizing ECM, which was expected, as this time point was within the late differentiation stage (Fig. 5i-p). There was a particularly high concentration of mineral phosphate in the mineralizing subclone on SPS 
(Fig. 5m), which is congruent with the phosphate:protein data (Fig. 4). The lowest amount of phosphate was observed in the nonmineralizing culture on uncoated MirrIR, at day 21 (Fig. 5p).

\section{Collagen accumulation}

The amount of collagen $\left(1350-1325 \mathrm{~cm}^{-1}\right)$ produced by day 1 was not significantly different across the four groups (Fig. 6). By day 21, the amount of deposited collagen was considerably less in both cell lines, possibly due to increased amount of non-collagenous proteins accumulated during the three weeks. Mineralizing osteoblasts on day 21 had also produced about twice the amount of collagen than nonmineralizing osteoblasts $(\mathrm{p}<0.001)$. More noticeably, mineralizing osteoblasts produced comparable amount of collagen irrespective of the substrate, whereas nonmineralizing cells cultured on SPS-coated MirrIR produced 38\% more collagen $(p<0.001)$ than those on uncoated MirrIR.

\section{E. Collagen maturity}

Ratios of mature $\left(\sim 1660 \mathrm{~cm}^{-1}\right)$ and immature $\left(\sim 1690 \mathrm{~cm}^{-1}\right)$ collagen cross-links (Fig. 7) as determined from the globar FTIRM spectra were very different across all the samples with respect to pre-osteoblast subclone and surface type. After 1 day of culture, the level of collagen cross-linking was not significantly different across all groups (Fig. 7). By day 21, however, there were notable differences between the mineralizing and nonmineralizing subclones. Overall, a $21-51 \%$ decrease $(\mathrm{p}<0.05)$ in collagen maturity 


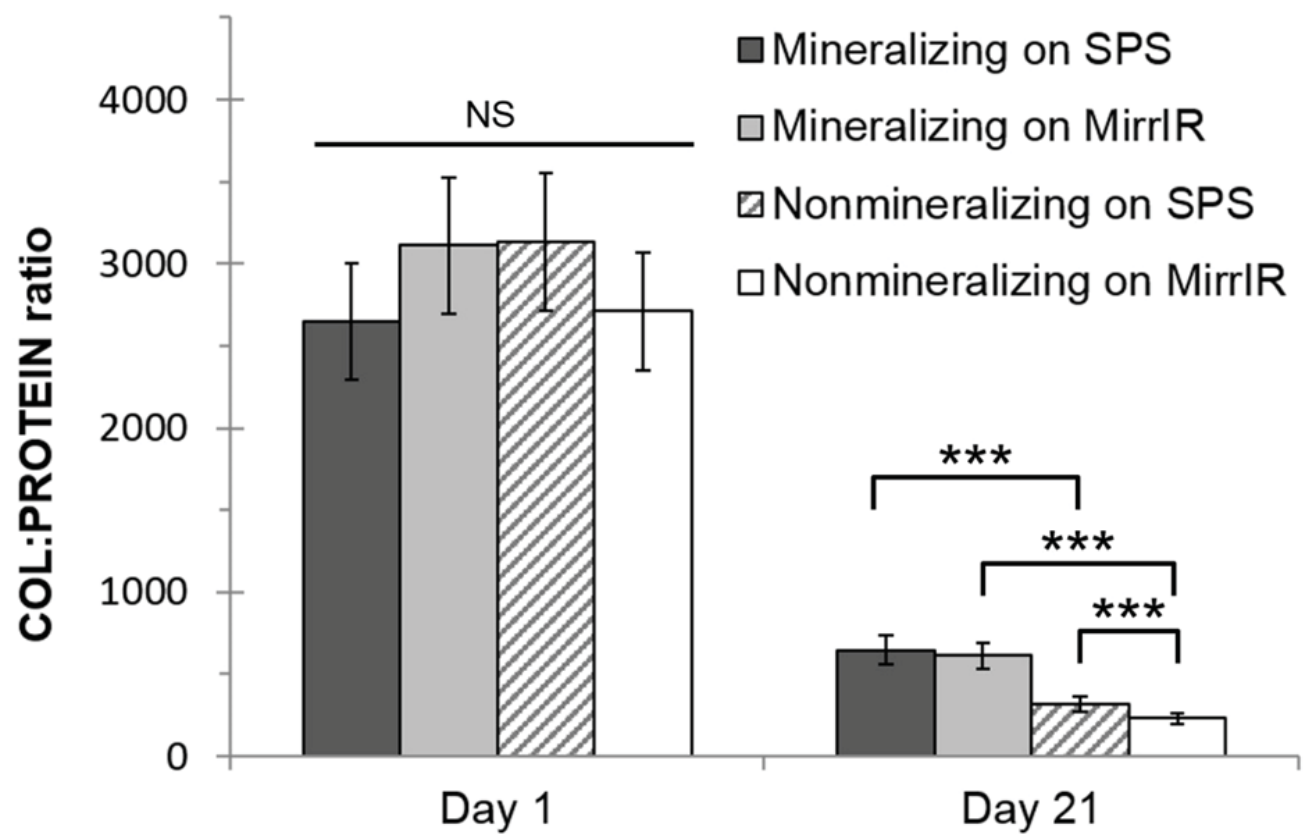

Figure 6. Collagen production (mean $\pm \mathrm{SE}$ ) calculated from collagen $\left(1350-1325 \mathrm{~cm}^{-1}\right)$ to protein (1700-1600 $\mathrm{cm}^{-1}$ ) ratios in mineralizing and nonmineralizing MC3T3-E1 cells on (A) SPS-coated and (B) uncoated MirrIR slides. Data were collected at beamline U2B at the NSLS. Levels of statistical significance are indicated by single $(*, p<0.05)$, double $(* *, \mathrm{p}<0.01)$, or triple $(* * *, \mathrm{p}<0.001)$ asterisks.

was observed for nonmineralizing cells compared to their mineralizing counterparts over the three-week period. There was no significant difference in collagen maturity on day 21 between the mineralizing subclone cultured on SPS compared to those cultured on uncoated MirrIR (Fig. 7). Additionally, compared to nonmineralizing cells cultured on SPS, collagen maturity was $52 \%$ higher $(\mathrm{p}<0.01)$ for the same subclone cultured on uncoated MirrIR (Fig. 7). Moreover, considerable increases ranging from $86 \%$ to $152 \%$ were observed between day 1 and day 21 for mineralizing cells cultured on either SPS $(\mathrm{p}=0.11)$ or uncoated MirrIR $(\mathrm{p}<0.001)$. In contrast, no changes in collagen maturity were observed for nonmineralizing cells cultured on SPS between day 1 and day 21 . However, 


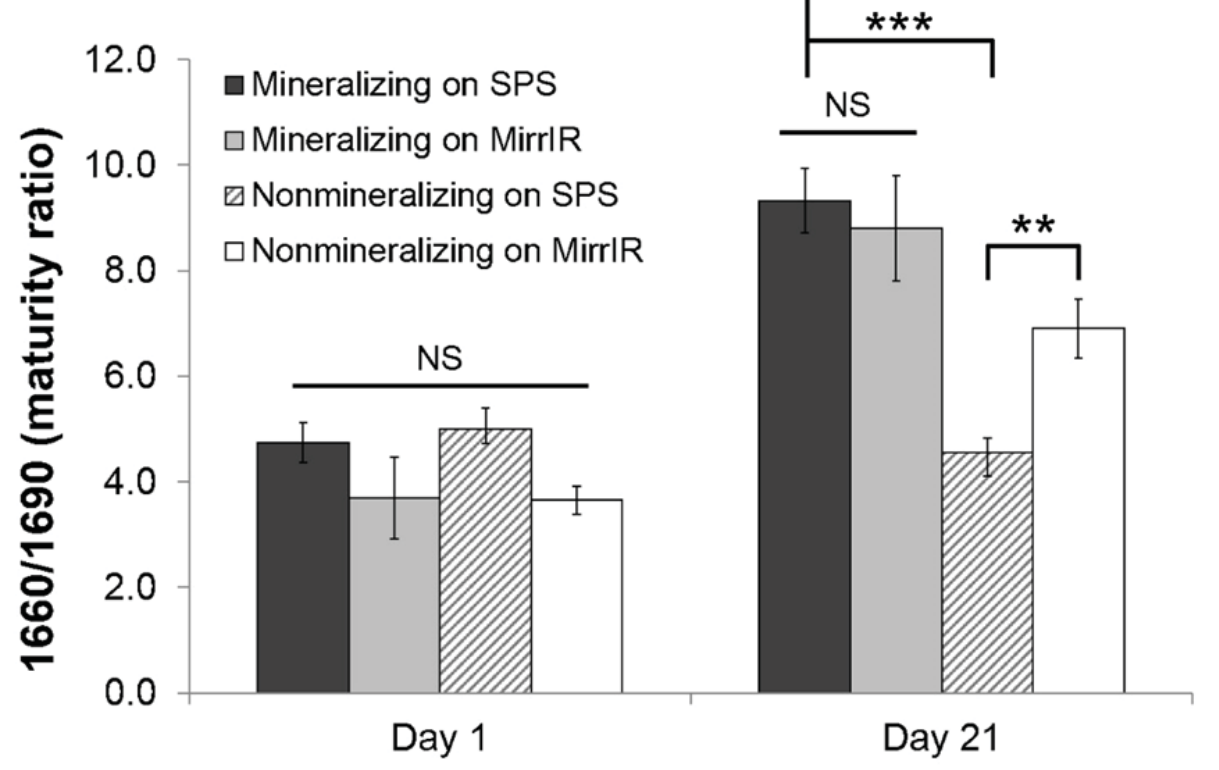

Figure 7. Calculated 1660:1690 spectroscopic ratio in MC3T3-E1 cells cultured for up to 21 days on SPS-coated and uncoated MirrIR slides. Values represent the mean \pm SE of up to 21 spectra collected at beamline U2B At the NSLS. Levels of statistical significance are indicated by single $(*, \mathrm{p}<0.05)$, double $(* *, \mathrm{p}<0.01)$, or triple $(* * *$, $\mathrm{p}<0.001)$ asterisks.

an $89 \%$ increase $(\mathrm{p}<0.01)$ was seen for nonmineralizing cells cultured for the same duration on uncoated MirrIR.

\section{IV.DISCUSSION}

Both the organic and inorganic matrices in bone are known to change during maturation until the animal is skeletally mature ${ }^{18}$. Type I collagen, which comprises approximately $90 \%$ of the organic matrix of bone ${ }^{19}$, develops during skeletal maturation and also orientates along the direction of the mechanical load ${ }^{20}$. Once the collagen fibers are formed in the ECM, they are further stabilized by the formation of inter- and 
intramolecular crosslinks that subsequently stabilize other immature collagen fibers ${ }^{21}$.

The relative amounts of mature and immature crosslinks are affected by the bone turnover rate ${ }^{22}$, and because the mechanical strength of bone is dependent on the stability of the collagen fibers ${ }^{23,24}$, post-translational modifications that affect collagen crosslinking as well as collagen strength and stiffness contribute to overall bone quality ${ }^{20,25}$. Indeed, crosslink concentration in the collagen of osteoporotic individuals with bone fractures is markedly reduced compared to healthy individuals ${ }^{26}$ and animals ${ }^{27}$. As the risk of osteoporosis-associated bone fractures is greatly influenced by age-associated deterioration in the structural integrity of bone, which results in an overall decrease in bone strength and bone mass ${ }^{28,29}$, collagen maturity may be a useful biomarker of bone quality.

Bone collagen is secreted by osteoblasts, which aggregate collagen fibers into fibrils ${ }^{26}$. In order for bone formation to proceed, collagen and other ECM proteins such as fibronectin must support the adhesion and spreading of pre-osteoblasts and actively promote their attachment and proliferation. Under in vitro conditions, osteoblast differentiation can be influenced by substrate surface functionality, and numerous studies have shown that material surfaces can impact the initial adsorption and remodeling dynamics of ECM proteins and, consequently, the exposure of cell adhesive domains essential for growth and differentiation ${ }^{30-32}$. Because the mineralization process of bone is initiated by the intrafibrillar nucleation of apatite crystals in preformed type I collagen fibrils ${ }^{2,6,33}$, protein-mineral interactions are crucial to the success of bone formation. As such, the chemical nature of collagen proteins can substantially affect bone mineralization. 
In this work, we investigated the ability of MirrIR slides to support the mineralization of murine pre-osteoblasts and the formation of a bone-like tissue both in the absence and presence of a polymer thin film. Based on a prior study in which we showed that in silico mineralization of MC3T3-E1 cells was greatly enhanced by coating the substrate with sulfonated polystyrene (SPS) ${ }^{5}$, we hypothesized that the functionalization of IR-compatible substrates with SPS would also alter the biomineralization of pre-osteoblasts. The two subclones of MC3T3-E1 pre-osteoblasts cultured on SPS-coated and uncoated MirrIR slides appeared confluent in the optical micrographs, indicating that the cells bonded very well to both substrates. This is in congruence with our previous observations that the same cell lines also bonded well to SPS-coated and uncoated silicon ${ }^{5}$. We were able to show, using synchrotron and globar FTIRM, that strongly mineralizing osteoblasts cultivated on SPS-coated MirrIR slides consistently produced much higher amounts of bone-like mineral after three weeks of differentiation. When bare MirrIR slides (without SPS coating) were used, the MC3T3E1 cells produced similar amounts of collagen but mineralized less extensively. These results indicate that SPS-coated MirrIR is much more conducive to bone biomineralization than uncoated MirrIR, a finding that is similar to our previous study in which SPS was shown to promote the initial development of a fibrillar ECM network in silico, which, when fully mineralized by the osteoblasts, resembles that of bone tissue in vivo $^{5}$. In contrast, subclone 24 MC3T3-E1 cells underwent minimal level of mineralization irrespective of the substrate surface, possibly due to their innate inability to differentiate properly ${ }^{34}$. 
Additionally, we observed that for cells that consistently produced a mineralized layer, their collagen maturity ratio increased substantially after being exposed to osteogenic medium for 3 weeks, as could be seen for the subclone 4 cells cultured on SPS ("Mineralizing on SPS" in Fig. 7). Morever, there was no significant difference between mineralizing cells on SPS-coated MirrIR vs. uncoated MirrIR. Taken together with the phosphate:protein ratio map (Fig. 5) and the collagen:protein ratio data (Fig. 6), these results suggest that although ECM remodeling by subclone 4 cells may not have been significantly altered by substrate surface modification, the mineral output was considerably different. In contrast to the mineralizing subclone 4 cells, collagen maturity of subclone 24 cells cultured on SPS did not change between days 1 and 21 ("Nonmineralizing on SPS" in Fig. 7). It was also interesting to note that by day 21, nonmineralizing cells on uncoated MirrIR reached a much higher collagen maturity ratio than the same subclone cultured on SPS-coated MirrIR, at a level that was close to 74$78 \%$ of the mineralizing subclone. The collagen remodeling process of subclone 24 cells appeared to be impaired by SPS, suggesting that intrinsic differences between the functionalized and bare MirrIR surfaces may have contributed differently to the organization of the ECM network. These differences may also have caused the subclone 4 cells to deposit less mineral on uncoated MirrlR. As such, collagen maturity alone may not be sufficient in explaining the varying degrees of mineralization we have observed between pre-osteoblasts cultured on MirrIR and SPS-MirrIR.

Numerous studies suggest that substrates with a water contact angle (WCA) between $60^{\circ}$ and $70^{\circ}$ are ideal for directing proliferation and other desired cellular behavior ${ }^{35-37}$. The SPS-coated MirrIR slides used in our study have a WCA of about $64^{\circ}$, 
which is in this optimal range. In contrast, uncoated MirrIR slides have a much lower WCA, $42^{\circ}$ (Table 1). Previous studies have reported that more focal adhesions are found in osteoblasts when cultured on tissue culture polystyrene, which has a contact angle of $\sim 50^{\circ}$, than when they are cultured on plasma-treated (contact angle $0^{\circ}$ ) or silane-treated (contact angle $105^{\circ}$ ) quartz ${ }^{38}$. Human fetal osteoblasts cultured on hydrophobically treated quartz also had a significantly higher expression of osteopontin, a late-stage bone differentiation marker ${ }^{39}$. It has been established that bone formation is dependent on the tight regulation of type I collagen as well as the non-collagenous ECM protein fibronectin, which plays a critical role in stabilizing and regulating the bone $\operatorname{ECM}^{40,41}$. Studies have shown that human plasma fibronectin adsorbs optimally on glass surface with a contact angle of $57^{\circ}{ }^{35}$. Therefore it is very likely that the uncoated MirrIR slides used in our study did not provide the most suitable culturing conditions needed for proper cell attachment, growth and differentiation of the MC3T3-E1 pre-osteoblast cells.

It has been suggested that the water packing capacity of collagen fibers can greatly determine the infiltration of liquid precursors into the intramolecular spaces, a critical event in the very early stages of collagen mineralization ${ }^{42,43}$. Moreover, there exists a close relationship between the amount of available water in any given space and the mineral deposition process of bone formation. Consequently, collagen packing is affected both by water that is within the fibrils and that which is extrafibrillar ${ }^{44,45}$. Mineral crystals can start to grow in the gap regions within the fibrils ${ }^{19}$, while at the same time mineral-protein complexes formed in the extrafibrillar space can diffuse inside and become transformed into organized crystalline arrays guided by the collagen structures ${ }^{46}$. It is possible that on uncoated MirrIR slides, although collagen remodeling 
was carried out by subclone 4 pre-osteoblasts, the microarchitecture of the extracellular network may not have been optimal for the infiltration of mineralization precursors due to the higher wettability of the substrate surface. As a result, mineral phosphate production was less extensive in the cultured osteoblasts.

This study was, to the best of our knowledge, the first to examine the materials properties of IR-compatible substrates for assessing in vitro osteoblast mineralization. Our results demonstrate that there is still a need for a more complete understanding of the role of surface modification of materials used in spectroscopic studies.

\section{SUMMARY AND CONCLUSIONS}

Two subclones of murine calvarial MC3T3-E1 cells were successfully cultivated on indium tin-oxide (ITO)-coated "MirrIR" microscope slides either uncoated or functionalized with a thin film of sulfonated polystyrene (SPS). Fourier-transform infrared microspectroscopy (FTIRM) analysis showed that osteoblast mineralization on SPS-coated substrates closely resembles naturally occurring bone apatite. We observed that the mineralizing subclone culture on SPS produced significantly more mineral (phosphate:protein ratio) after 21 days of exposure to osteogenic medium, compared to the same cell line culture on bare ITO. The level of mineral accumulation in the nonmineralizaing cells did not vary significantly between days 1 and 21 . We were also able to characterize the spatial distribution of mineral production in these samples, which clearly show that areas of the osteoblast culture that otherwise appear homogenous in light micrographs in fact have clusters of mineral accumulation. After 21 days of culture, the strongly mineralizing MC3T3-E1 subclone 4 cells produced similar amounts of 
collagen on both substrates but higher amounts of mineral phosphate when cultured on SPS-coated MirrIR. These same cells, when cultured directly onto the nonfunctionalized MirrIR surface, produced substantially less mineral. The nonmineralizing MC3T3-E1 subclone 24 cells produced significantly less collagen and negligible amounts of mineral phosphate for the entire duration of the experiment. Collagen maturity ratio, as defined by the $1660 / 1690$ spectroscopic ratio, increased substantially from day 1 to day 21 for subclone 4 cells cultured on either SPS-coated or uncoated MirrIR and remained unchanged for subclone 24 cells cultured on SPS-coated MirrIR. There was a less notable increase in collagen maturity ratio for subclone 24 cells cultured on uncoated MirrIR. Taken together, these results suggest that SPS-treatment of the MirrIR surface may have influenced the collagen remodeling process, thereby enhancing osteoblast mineralization in the long term.

\section{ACKNOWLEDGMENTS}

The MC3T3-E1 cell lines were kindly donated by B. Frenkel and L. Bonewald. We are very grateful to M. Glimcher for preparing the octacalcium phosphate. This work was supported by NIH (AR49286, AR52379 and AR61821), National Space Biomedical Research Institute through NASA contract, and U.S. Army Medical Research. The National Synchrotron Light Source at Brookhaven National Laboratory was supported under U.S. DOE Contract DE-AC02-98CH10886. 
1. R. Marcus, S. Majumder. 2001. The Nature of Osteoporosis. San Diego: Academic Press

2. P. Fratzl, H. S. Gupta, E. P. Paschalis, P. Roschger. Journal of Materials Chemistry 14, 2115 (2004).

3. B. A. Gokhale J, Robey P. 2001. The Biochemistry of Bone. San Diego: Academic Press

4. L. F. Bonewald, S. E. Harris, J. Rosser, M. R. Dallas, S. L. Dallas, et al. Calcified Tissue International 72, 537 (2003).

5. Y. Meng, Y. Qin, E. DiMasi, e. al. TISSUE ENGINEERING PART A 15, 355 (2009).

6. J. Christoffersen, W. J. Landis. Anatomical Record 230, 435 (1991).

7. C. Rey, A. Hina, A. Tofighi, M. J. Glimcher. Cells and Materials 5, 345 (1995).

8. H. Sudo, H. A. Kodama, Y. Amagai, S. Yamamoto, S. Kasai. Journal of Cell Biology 96, 191 (1983).

9. A. L. Boskey, N. P. Camacho, R. Mendelsohn, S. B. Doty, I. Binderman. Calcified Tissue International 51, 443 (1992).

10. M. E. Faillace, R. J. Phipps, L. M. Miller. Calcified Tissue International 92, 50 (2013).

11. A. L. Boskey, N. Pleshko, S. B. Doty, R. Mendelsohn. Cells and Materials 2, 209 (1992).

12. E. Durchschlag, E. P. Paschalis, R. Zoehrer, P. Roschger, P. Fratzl, et al. Journal of Bone and Mineral Research 21, 1581 (2006).

13. R. Mendelsohn, A. Hassankhani, E. Dicarlo, A. Boskey. Calcified Tissue International 44, 20 (1989).

14. L. M. Miller, V. Vairavamurthy, M. R. Chance, R. Mendelsohn, E. P. Paschalis, et al. Biochimica Et Biophysica Acta-General Subjects 1527, 11 (2001).

15. A. S. Posner, F. Betts. Accounts of Chemical Research 8, 273 (1975).

16. M. M. Gentleman, E. Gentleman. International Materials Reviews 59, 417 (2014).

17. K. M. Gough, D. Zelinski, R. Wiens, M. Rak, I. M. C. Dixon. Analytical Biochemistry 316, 232 (2003).

18. H. Isaksson, T. Harjula, A. Koistinen, J. Ivarinen, K. Seppanen, et al. Journal of Orthopaedic Research 28, 1626 (2010).

19. E. Beniash. Wiley Interdisciplinary Reviews-Nanomedicine and Nanobiotechnology 3, 47 (2011).

20. S. Viguet-Carrin, P. Garnero, P. D. Delmas. Osteoporosis International 17, 319 (2006).

21. M. J. Turunen, S. Saarakkala, H. J. Helminen, J. S. Jurvelin, H. Isaksson. Journal of Orthopaedic Research 30, 435 (2012).

22. D. B. Burr. Bone 31, 8 (2002).

23. H. Oxlund, M. Barckman, G. Ortoft, T. T. Andreassen. Bone 17, 365S (1995).

24. C. C. Danielsen, T. T. Andreassen, L. Mosekilde. Calcified Tissue International 39, 69 (1986).

25. X. Banse, J. P. Devogelaer, A. Lafosse, T. J. Sims, M. Grynpas, A. J. Bailey. Bone 31, 70 (2002).

26. H. Oxlund, L. Mosekilde, G. Ortoft. Bone 19, 479 (1996).

27. A. J. Bailey, S. F. Wotton, T. J. Sims, P. W. Thompson. Connective Tissue Research 29, 119 (1993).

28. D. Farlay, M. E. Duclos, E. Gineyts, C. Bertholon, S. Viguet-Carrin, et al. Plos One 6, (2011). 
29. A. M. Parfitt. Clinical Obstetrics and Gynecology 30, 789 (1987).

30. B. G. Keselowsky, D. M. Collard, A. J. Garcia. Biomaterials 25, 5947 (2004).

31. B. Keselowsky, D. Collard, A. Garcia. Proceedings of the National Academy of Sciences of the United States of America 102, 5953 (2005).

32. L. Y. Liu, S. F. Chen, C. M. Giachelli, B. D. Ratner, S. Y. Jiang. Journal of Biomedical Materials Research Part A 74A, 23 (2005).

33. J. Mahamid, A. Sharir, L. Addadi, S. Weiner. Proceedings of the National Academy of Sciences of the United States of America 105, 12748 (2008).

34. D. Wang, K. Christensen, K. Chawla, G. Z. Xiao, P. H. Krebsbach, R. T. Franceschi. Journal of Bone and Mineral Research 14, 893 (1999).

35. T. Groth, G. Altankov. Biomaterials 17, 1227 (1996).

36. J. M. Schakenraad, H. J. Busscher, C. R. H. Wildevuur, J. Arends. Cell Biophysics 13, 75 (1988).

37. Y. Tamada, Y. Ikada. Journal of Biomedical Materials Research 28, 783 (1994).

38. X. M. Liu, J. Y. Lim, H. J. Donahue, R. Dhurjati, A. M. Mastro, E. A. Vogler. Biomaterials 28, 4535 (2007).

39. J. Y. Lim, A. F. Taylor, Z. Y. Li, E. A. Vogler, H. J. Donahue. Tissue Engineering 11, 19 (2005).

40. A. M. Moursi, C. H. Damsky, J. Lull, D. Zimmerman, S. B. Doty, et al. Journal of Cell Science 109, 1369 (1996).

41. F. Shi, J. Harman, K. Fujiwara, J. Sottile. American Journal of Physiology-Cell Physiology 298, C1265 (2010).

42. H. Colfen. Nature Materials 9, 960 (2010).

43. A. Dey, P. Bomans, F. Muller, J. Will, P. Frederik, et al. Nature Materials 9, 1010 (2010).

44. R. A. Robinson, S. R. Elliott. Journal of Bone and Joint Surgery-American Volume 39, 167 (1957).

45. S. Lees. Connective Tissue Research 16, 281 (1987).

46. A. George, A. Veis. Chemical Reviews 108, 4670 (2008). 

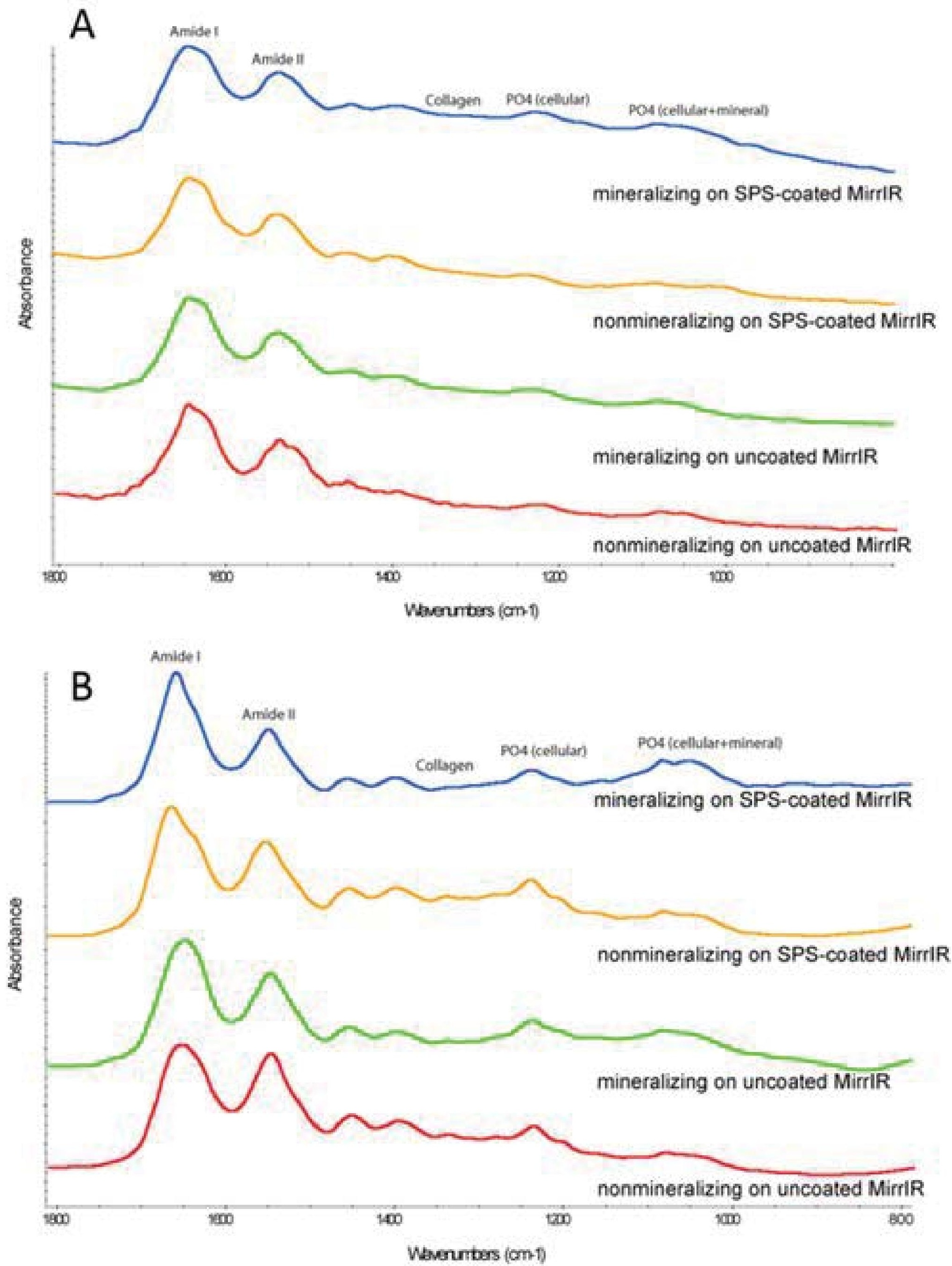


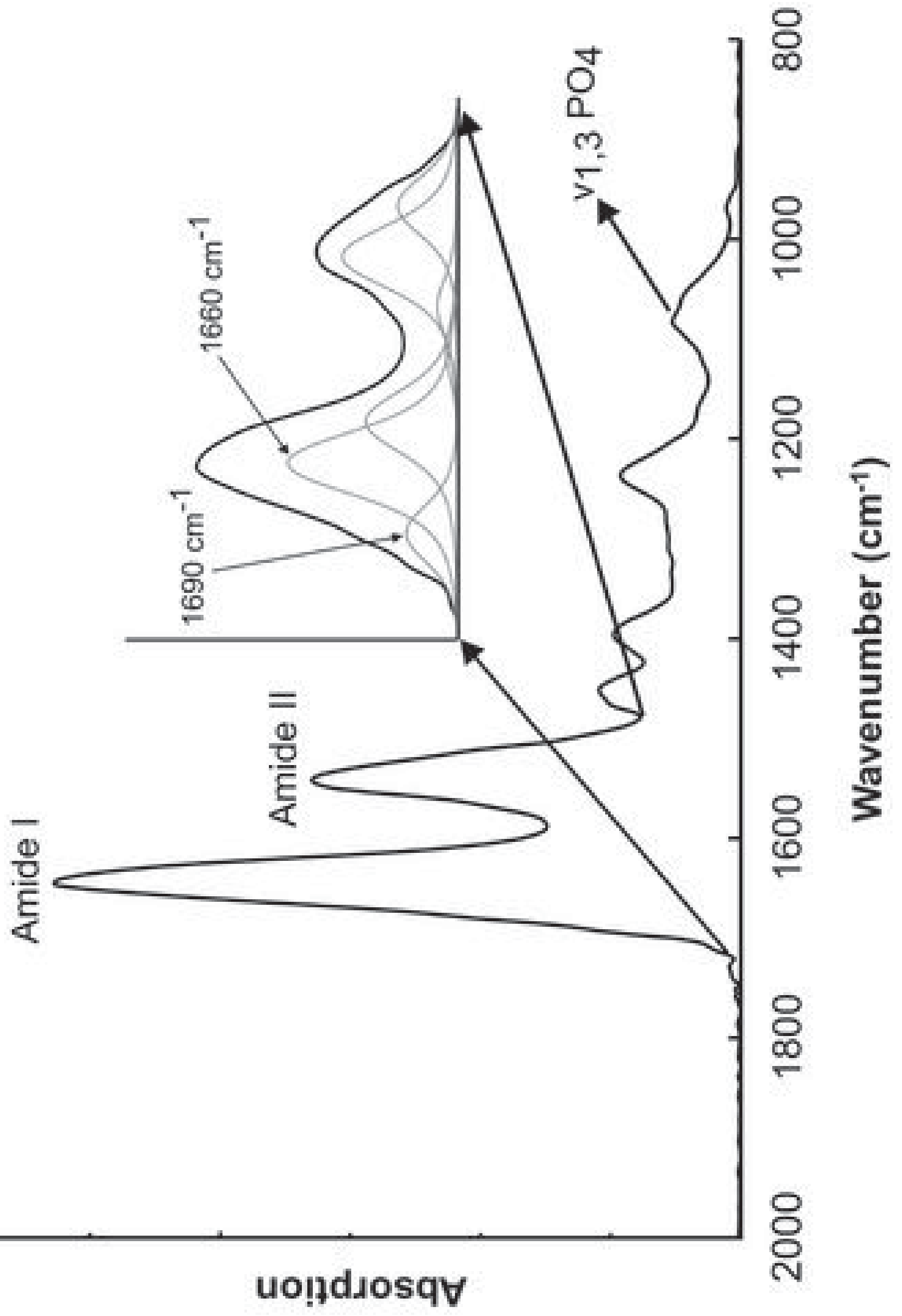




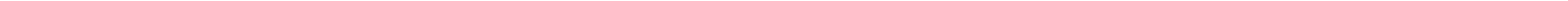



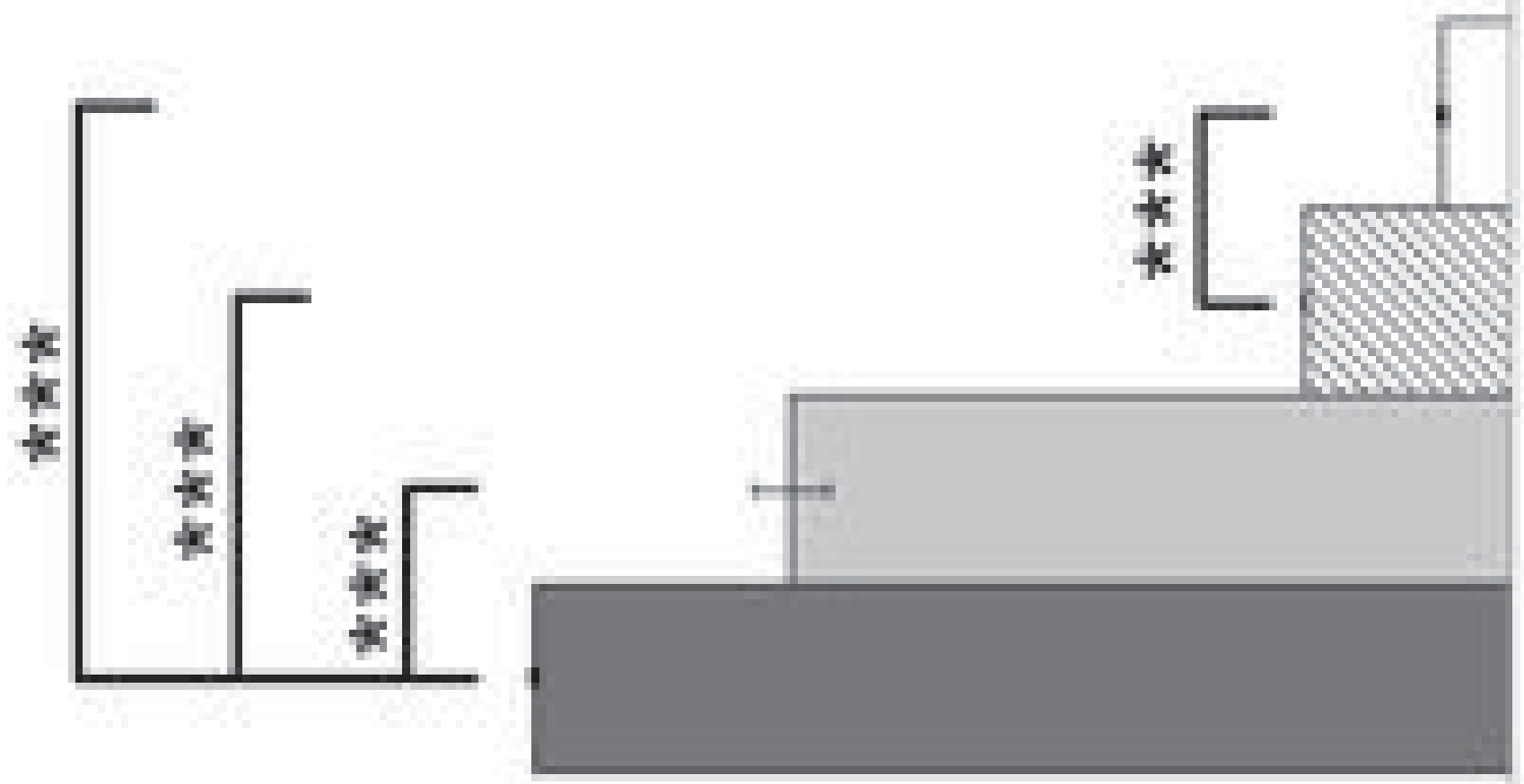

14
5
7
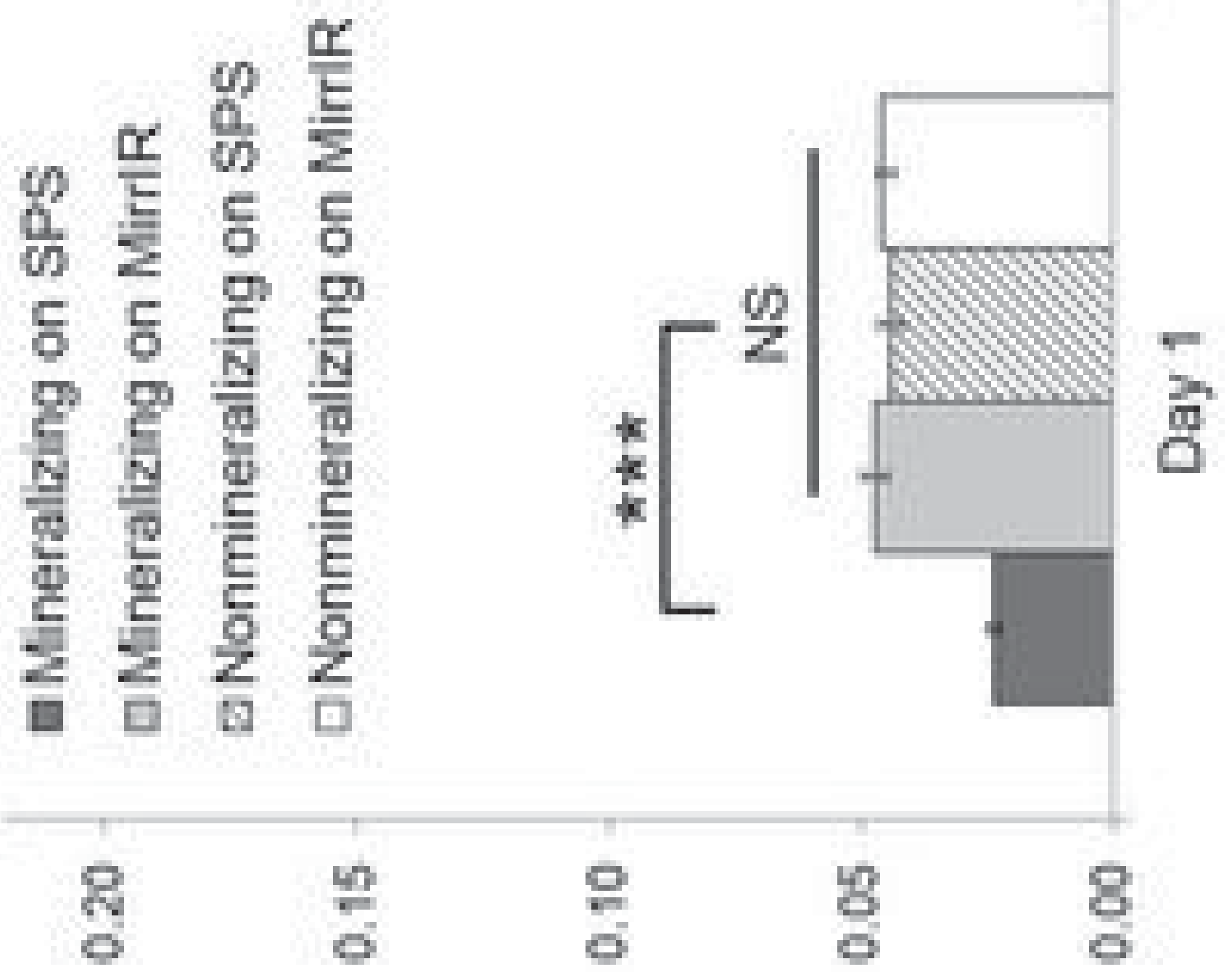

8 
눙

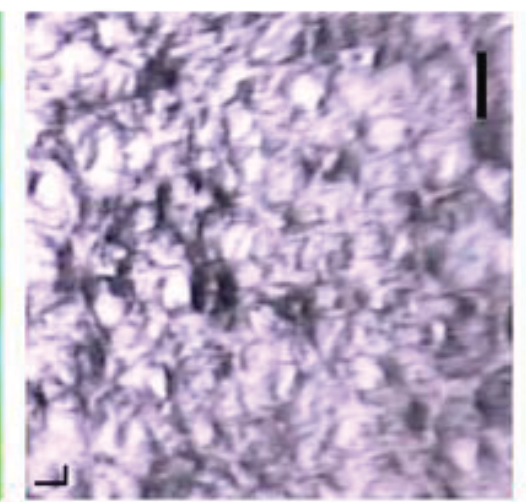

.
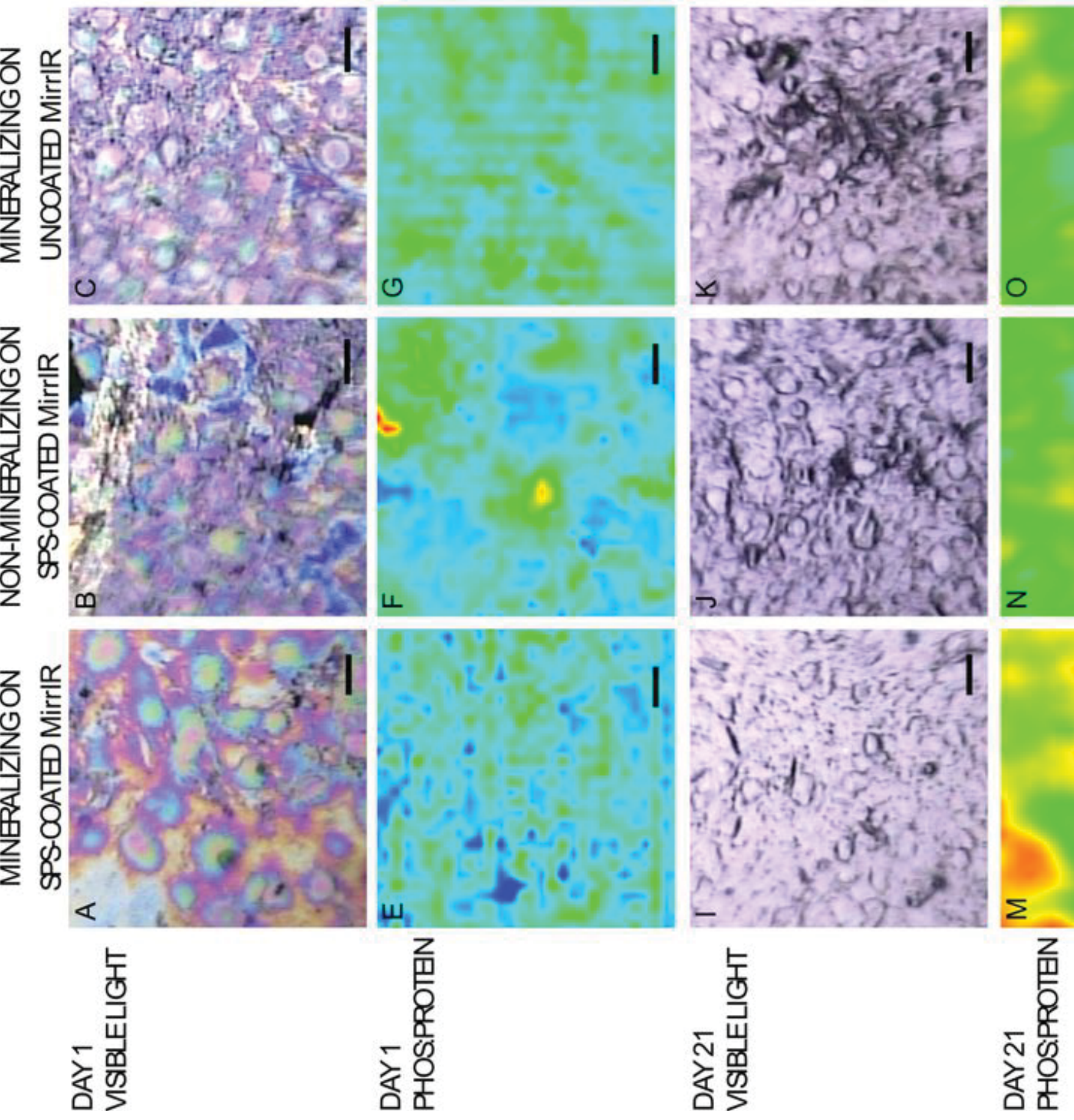


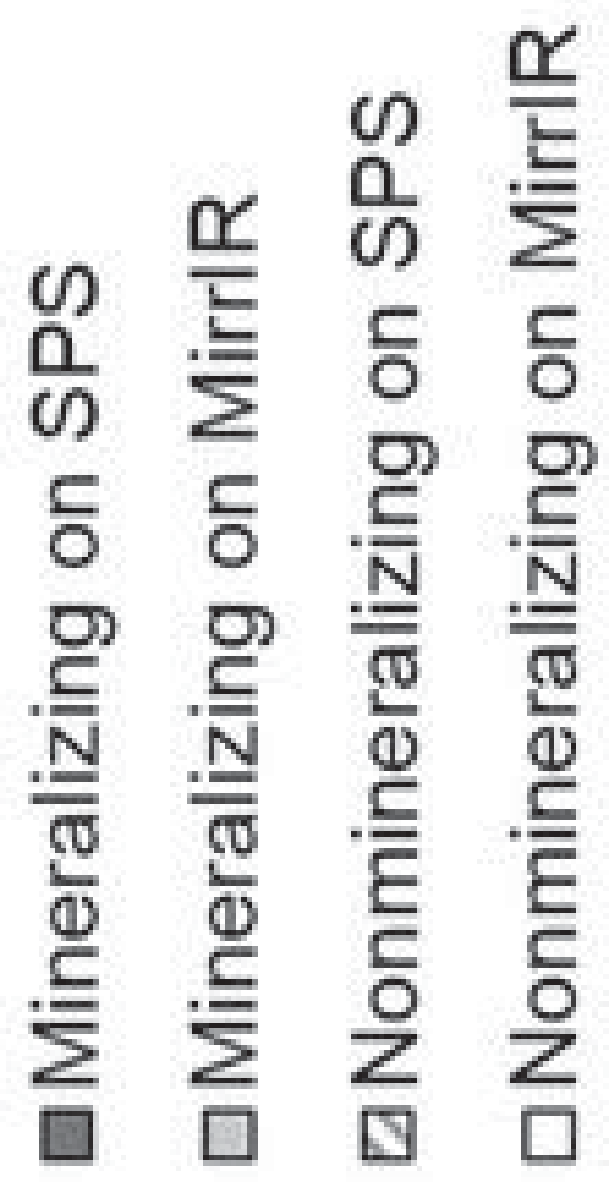
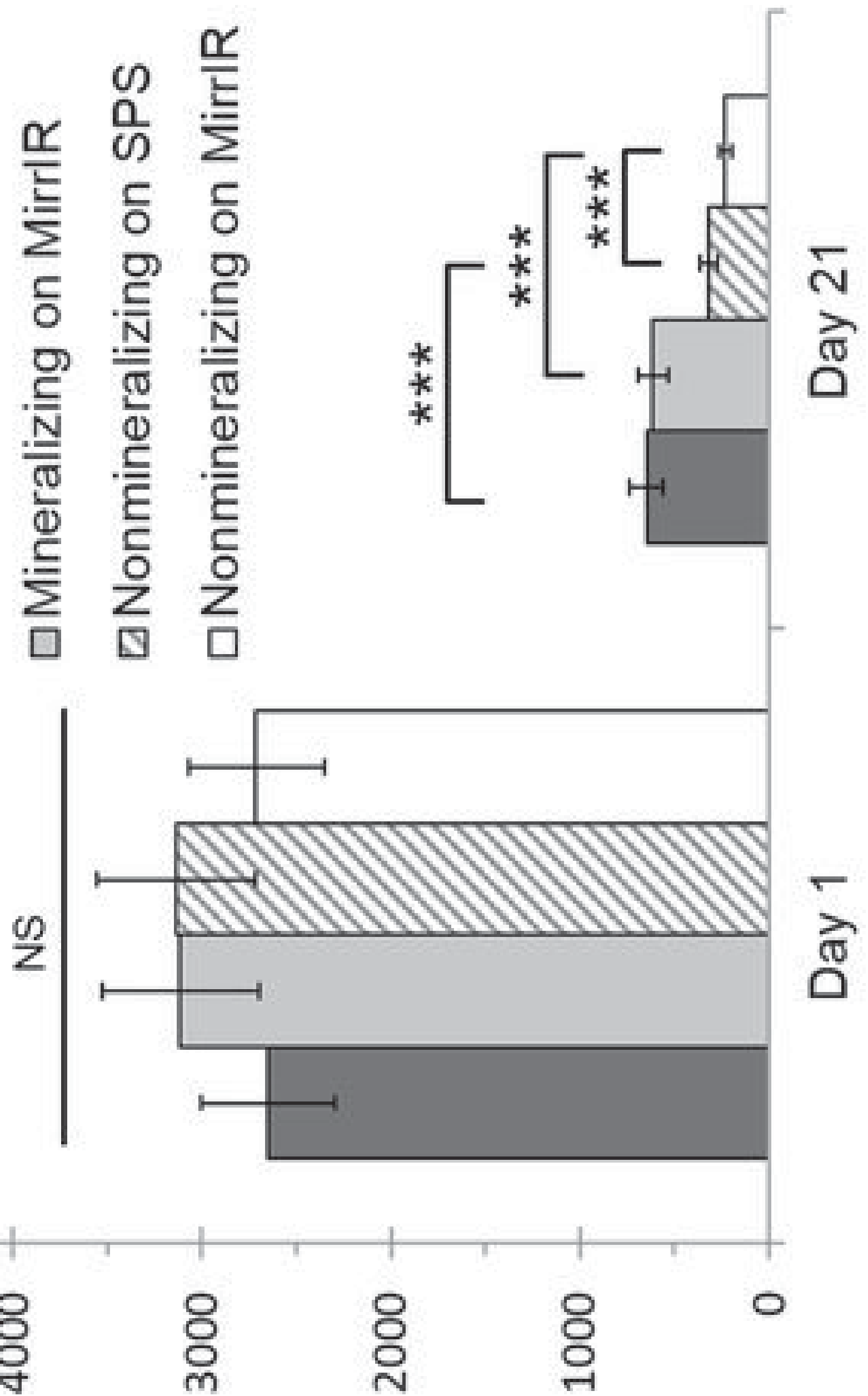

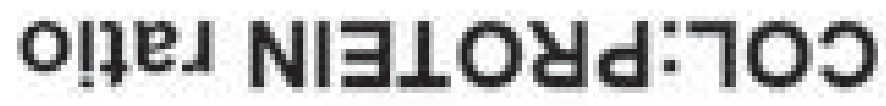




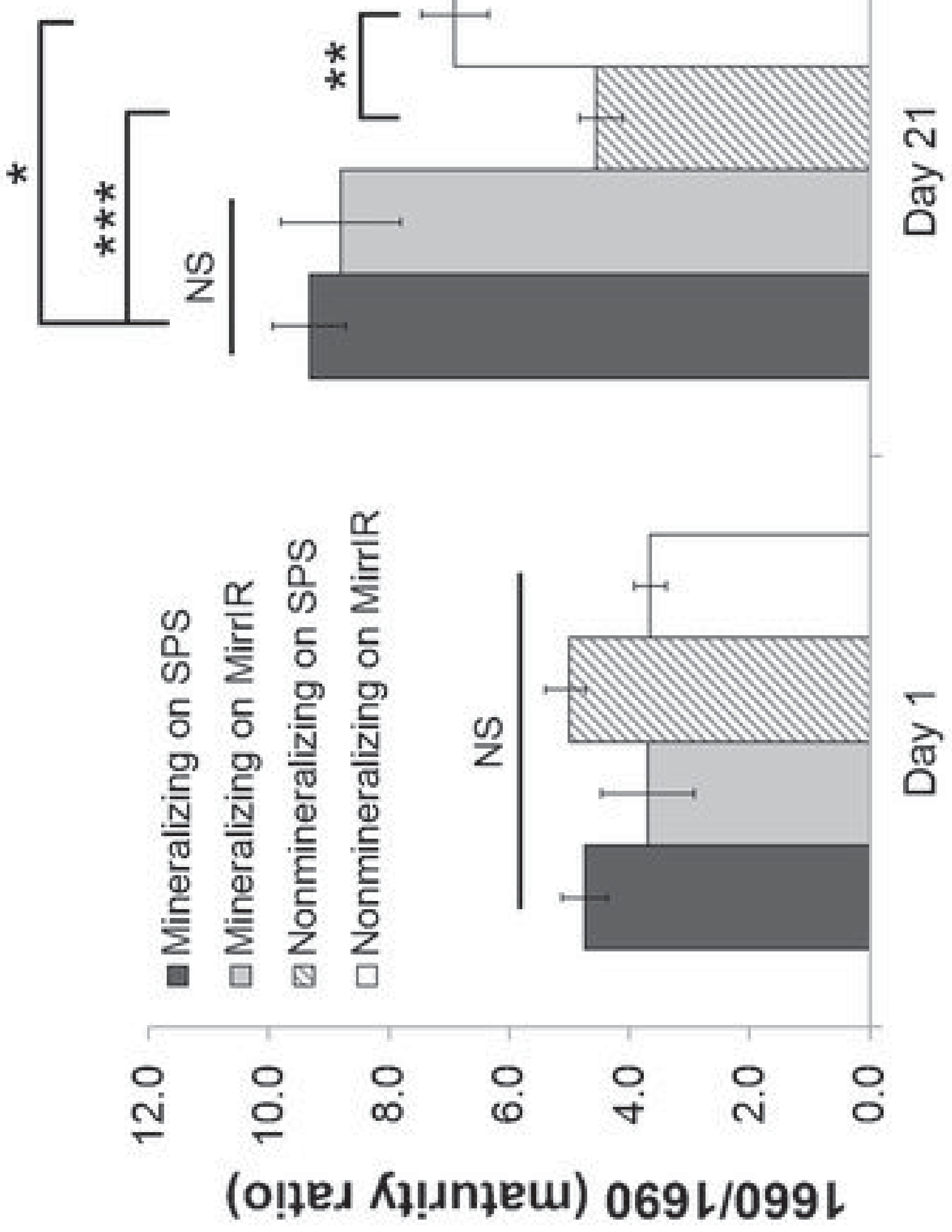

